TI 2012-082/3

Tinbergen Institute Discussion Paper
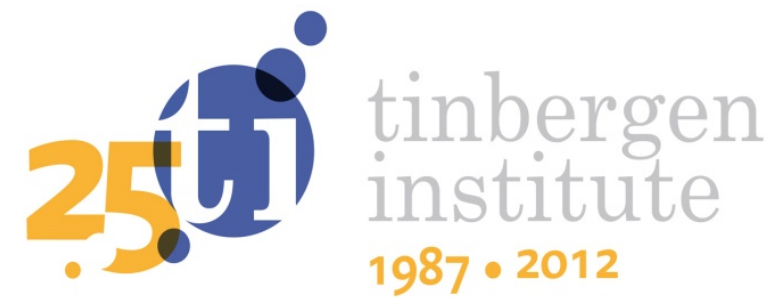

\title{
The Impact of a Culturally Diverse Workforce on Firms' Market Size: An Empirical Investigation on Germany
}

\author{
Stephan Brunow \\ Peter Nijkamp
}

I Institute for Employment Research, Nuremberg/Germany;

2 Faculty of Economics and Business Administration, VU University, Amsterdam/Netherlands, and Tinbergen Institute. 